\title{
Bioactive support for cell cultivation and potential grafting. Part 1: Surface modification of 2-hydroxyethyl methacrylate hydrogels for avidin immobilization
}

\author{
Radka Hobzova, ${ }^{12 *}$ Martin Pradny, ${ }^{12}$ Nazym M. Zhunusbekova, ${ }^{1}$ Jakub Sirc, ${ }^{12}$ Vilem \\ Guryca, ${ }^{1}$ Jiri Michalek ${ }^{12}$
}

${ }^{1 *}$ Institute of Macromolecular Chemistry, Academy of Sciences of the Czech Republic, Heyrovsky sq. 2, 162 06, Prague 6, Czech Republic; tel: +420-296-809410; e-mail: hobzova@imc.cas.cz.

${ }^{2}$ Centre for Cell Therapy and Tissue Repair, 2nd Faculty of Medicine, Charles University in Prague, V Uvalu 84, 150 06, Prague 5, Czech Republic.

(Received: 22 May, 2009; published:11 May, 2011)

\begin{abstract}
Synthetic hydrogels are often used in biomedical applications as many of them are compatible with living tissue and moreover they can meet most criteria for artificial tissue properties. For applications in tissue engineering modification of polymer surface using some bioactive compounds (e.g. saccharides, proteins) for promoting the process of cell adhesion and proliferation is widely used. In this work, a series of modified hydrogels was prepared by three different methods: by copolymerization of 2-hydroxyethyl methacrylate with methacrylic acid, by hydrolysis and oxidation of poly(2-hydroxyethyl methacrylate) to obtain carboxyl-rich supports. The influence of the reaction conditions of the hydrogel surface treatment on the total carboxylic group content and the swelling degree was studied. The modified hydrogels were characterized by attenuated total reflectance FT-IR spectroscopy and refractive index measurements. Obtained carboxylic groups on the hydrogel surface have allowed the immobilization of avidin in two ways: 1) electrostatically through dissociated carboxylic groups and 2) covalently bonded through activated carboxylic groups by $\mathrm{N}$ hydroxysuccinimide. The capacity of hydrogels for avidin immobilization was determined by Bradford spectrophotometric method. The results so far obtained from the preliminary biological tests showed that immobilized avidin on the hydrogel surface provides better adhesion and proliferation of keratinocytes compared to supports without avidin.
\end{abstract}

\section{Introduction}

A substantial progress in tissue engineering and cell therapy in recent decades has necessitated development of materials suitable for regeneration and replacement of damaged tissue. The material should serve as a synthetic extracellular matrix, which provides adhesion and proliferation of cells and affords stimuli, which control the growth and formation of the tissue.

Interaction of cells with polymer substrates is a complex process, where several chemical and physical factors play the key role. Many studies have been focused on improving the affinities of cells to synthetic surfaces, the results of which are summarized in reviews [1-5]. Most types of cells are able to realize their physiological functions so long as they are well anchored to substrate. Synthetic supports are mostly not suitable for cell adhesion and cultivation as cells require the presence of 
biologically active pro-adhesive moieties (e.g. proteins or saccharides) on the surface of polymer supports, which are recognized and decoded by cell surface receptors. Due to their inert nature, synthetic polymers generally need to undergo surface functionalization enabling the immobilization of bioactive compounds.

The most commonly used methods for immobilization of biologically active compounds on polymer surfaces are adsorption via non-specific interaction (hydrophobic), specific interaction (electrostatic), and covalent attachment using reactive groups in the polymer [1-3]; they are schematically shown in Fig. 1a for avidin. Although non-covalent immobilization is desirable in some applications, covalent attachment offers some advantages providing the most stable bond between the bioactive compound and the functionalized polymer surface and avoiding possible desorption on $\mathrm{pH}$ changes during subsequent procedures.

One of the possible approaches of polymer surface modification with bioactive compounds consists in utilization of an avidin-biotin binding system. The avidin-biotin technique has been extensively applied in biological analysis, such as in affinity chromatography, histochemistry, diagnostics, immunoassay, and drug delivery, with excellent results and high selectivity [6]. Avidin is a glycoprotein found in the egg white with four identical binding sites for biotin (vitamin $\mathrm{H}$ ), whereas the complex avidin-biotin represents one of the strongest non-covalent type of binding $\left(\mathrm{Ka} \sim 10^{15} \mathrm{Imol}^{-1}\right)[6]$.

On the polymer surface modified with avidin, biotinylated ligands containing bioactive moieties can be easily anchored (Fig. 1b). Thus tailor-made cultivation supports for the desired cell type can be prepared. This approach utilizes commercial availability of a number of biologically active compounds in the biotinylated form or of their possible preparation using commercially available biotinylated kits.

In the last few years, several examples of avidin immobilization on different surfaces have been described [7-12]. It was demonstrated that the approach utilizing the interaction between avidin-coated surfaces and biotinylated cells can enhance initial cell adhesion, cell spreading rate, and the strength of cell attachment. Thus, Tsai explored the cultivation process of chondrocytes on the surface of biodegradable polymers such as poly(L-lactic acid), poly(DL-lactic acid), and polycaprolactone [7-8], Kojima investigated adhesion of Hep G2 cells on the flat PLLA surfaces and highly porous three-dimensional scaffolds [9], and Reichert's group reported the studies on endothelial cell attachment to the surfaces of glass slides, Mylar ${ }^{\mathrm{TM}}$ and Teflon ${ }^{\mathrm{TM}}[10]$. Several studies focusing on the covalent attachment of avidin on the surfaces have been reported, where silicon wafers or tissue-cultured polystyrene with carboxylcontaining interlayer were modified by avidin via formation of covalent bonds between $\mathrm{COOH}$ groups and $\mathrm{NH}_{2}$ groups of avidin [11-12].

Synthetic hydrogels are often used in biomedical applications as they are known for their non-toxicity and they can meet most criteria for artificial tissue properties. Moreover, variety in chemical composition of hydrogel enables to prepare materials with physical and chemical properties (e.g. mechanical behaviour, swelling degree, optical and transport properties, etc.) suitable for a specific application [4-5,13-14]. However, for applications as cultivation supports, hydrogels may show in comparison with some commonly used materials (e.g. TK PS) a reduced adhesion and proliferation of cells and therefore it is desirable to promote the cell response by surface modification using the bioactive compounds [15]. 
The aim of this work is to prepare a universal cultivation support based on hydrogel, enabling immobilization of various bioactive motifs, and therefore targeted cultivation of a wide scale of cells. Appropriate bioactive motif is incorporated to the hydrogel structure by the reaction of its biotinylated form with avidin immobilized on the hydrogel surface forming the complex avidin-biotin (Fig. 1b). Herein, we report in detail the ways of the preparation of hydrogels containing immobilized avidin on their surface. For this purpose, poly(2-hydroxyethyl methacrylate) (poly(HEMA)) hydrogels were modified by copolymerization with methacrylic acid, hydrolysis or oxidation to obtain a carboxyl-rich hydrogel support. Subsequently, avidin is immobilized via the present carboxylic groups to the hydrogel surface through electrostatic forces or covalent bonds.

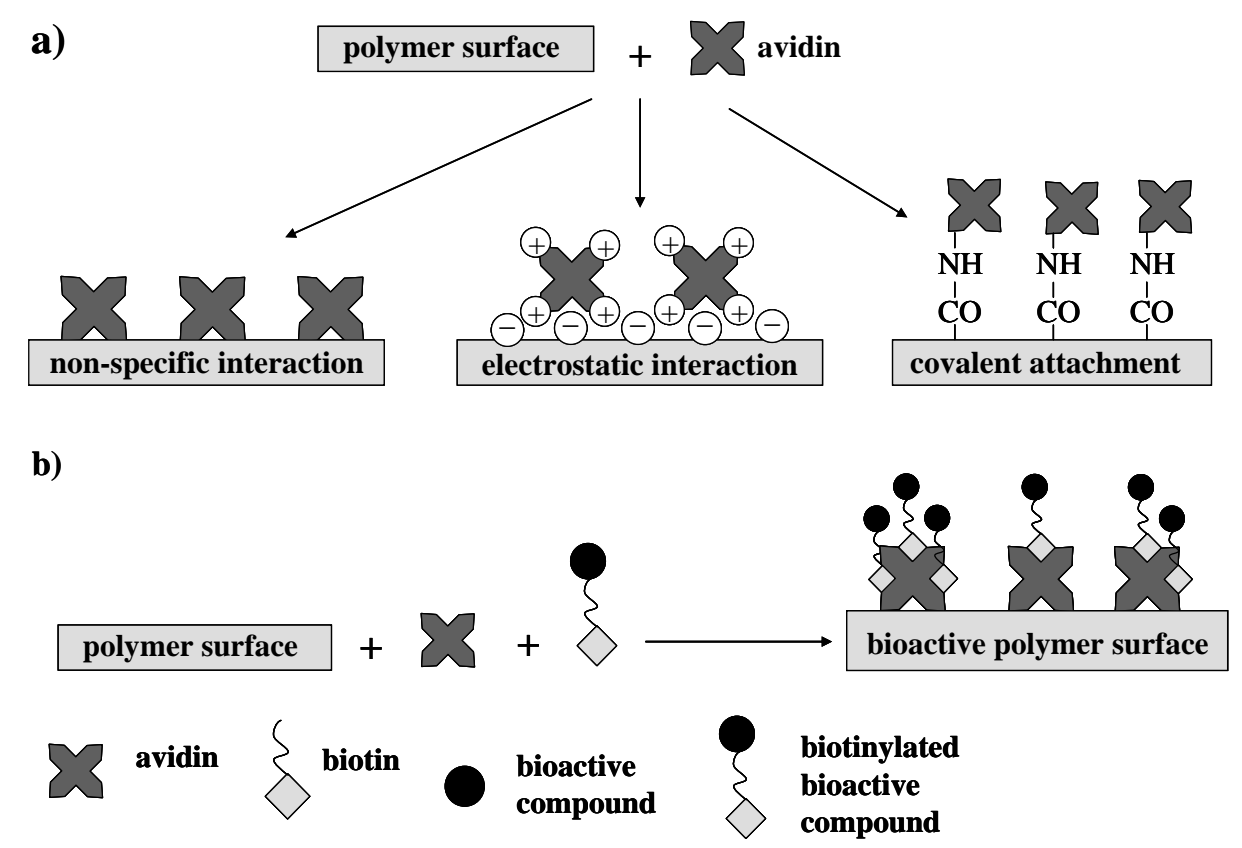

Fig. 1.a) Methods of avidin immobilization on a polymer surface. b) Formation of a bioactive polymer surface through complex avidin-biotin.

\section{Results and discussion}

In this work, as starting and comparative material we have chosen poly(HEMA) hydrogel, which is known as a good biocompatible material widely used in medicine [16-18]. The degree of hydrophilicity of this material enables protein adsorption on its surface through non-specific interactions. In our previous work [19] we studied the process of protein adsorption on macroporous hydrogels; the amount of nonspecifically adsorbed avidin was $8.3 \mathrm{mg}$ per gram of dry hydrogel. The amount of immobilized avidin on the surface of two-dimensional (non-porous) hydrogel is, however, approximately one order lower compared to macroporous hydrogel due to its lower specific surface. In addition, non-specific adsorption may cause some difficulties, such as the potential replacement of adsorbed avidin by other proteins (e.g. albumin) present in culture media or blood plasma. It was found that avidin and albumin show a comparable ability to adsorb on the surface of non-charged macroporous hydrogels (for albumin, $8.75 \mathrm{mg} / \mathrm{g}$ dry hydrogel) [19]. Albumin represents a protein with low biological activity and hence the biological response of the cells to such supports could be significantly reduced. 
Therefore, our attention has been predominantly focused on the other methods of avidin immobilization, which utilize electrostatic interactions or covalent attachment. Electrostatic sorption of proteins to the polymer surface can be enhanced by the presence of the surface charge. Since avidin has $\mathrm{pl} 10.5$, it can react with negatively charged species, e.g. carboxylate groups. In this case, the amount of proteins immobilized on macroporous hydrogels has increased about thirty times [19]. The attachment of proteins to the polymer surface via covalent bonds can be realized by the reaction of the amino groups in proteins and reactive groups in the polymer, e.g. activated carboxylic groups.

The introduction of carboxylic groups into the polymer structure can be achieved by several methods. In this work, we have explored three different approaches, namely copolymerization of HEMA with MA, hydrolysis and oxidation of poly(HEMA).

\section{Copolymerization of HEMA and MA}

Homogenous copolymers were prepared by copolymerization of a mixture of HEMA and MA, where the MA content varied from 0.012 to $9.22 \mathrm{mmol} / \mathrm{g}$. For electrostatic interactions between hydrogel and avidin to occur, carboxylic groups of MA units must be converted to the dissociated form, which was carried out in this work by neutralization with sodium hydrogencarbonate. The resulting copolymers poly(HEMA-co-MANa) - exhibit a very high swelling capacity compared to copolymers, where MA is not ionized. It follows from Fig. 2 that with increasing MANa content the swelling degree (SD) initially increasing very steeply; at MANa content $0.6 \mathrm{mmol} / \mathrm{g} \mathrm{SD}$ already reaches $90 \%$, and then remains almost constant. In the case of these copolymers, an increase in swelling capacity, however, causes the deterioration of mechanical strength (from the point of view of their handling). On the basis of our previous experience, it was found that the limiting content of water is around $75 \%$ (corresponding to the MANa content $0.35 \mathrm{mmol} / \mathrm{g}$ ) for maintaining sufficient mechanical strength (to avoid the breaking during handling) required for subsequent potential use.

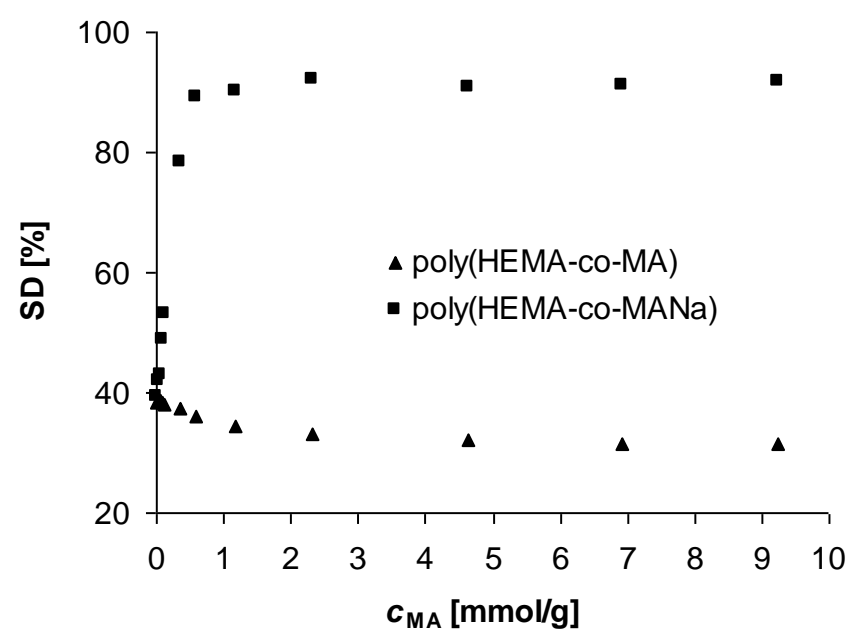

Fig. 2. The dependence of the swelling degree (SD) in equilibrium swollen poly(HEMA-co-MA) and poly(HEMA-co-MANa) hydrogels on the MA or MANa content $\left(c_{\mathrm{MA}}\right)$. 


\section{Surface Modification of Poly(HEMA)}

The deterioration of mechanical strength with growing MANa content can be overcome, so that poly(HEMA) hydrogel is modified by a hydrolytic or oxidation reaction predominantly on the surface. In this way, a non-homogenous material arises in which the concentration of carboxylic groups increases towards the surface. Moreover, the material brings a greater potential for protein immobilization and the low-swelling bulk allows keeping acceptable "handling". However, it is difficult to ascertain the depth of surface treatment. For the purpose of this work, we consider as fully sufficient to characterize hydrogels by the swelling degree, the total content of carboxylic groups and by the amount of immobilized avidin. The requirements such as low swelling degree and the highest $\mathrm{COOH}$ content, however, are contradictory, so it is always necessary to find a compromise.

The extent of modification reaction was estimated from the $\mathrm{COOH}$ content by three different methods: gravimetrically from the weight difference of the hydrogel before and after hydrolysis according to Equation 2, from the $\mathrm{Na}$ analysis for sodium salts and by potentiometric titration. The carboxylic group behaves as a weak acid which can be converted to its $\mathrm{Na}^{+}$form by the reaction with $\mathrm{NaHCO}_{3}$ and back into its $\mathrm{H}^{+}$ form with an excess of $\mathrm{HCl}$. The carboxylic group content was calculated from the difference in concentration of $\mathrm{NaHCO}_{3}$ solution before and after immersion of the hydrogel in $\mathrm{H}^{+}$form.

The accuracy of the used methods has been verified on poly(HEMA-co-MA) copolymers, where the known composition of the monomer mixture was compared with the results obtained from titration and elemental analysis. The differences did not exceed $\pm 7 \%$, which can be regarded as a satisfactory result, which indicates a possible error in the determination of the $\mathrm{COOH}$ content in poly(HEMA) modified by hydrolysis and oxidation.

\section{Hydrolysis of Poly(HEMA)}

Alkaline hydrolysis of 2-hydroxyethyl ester side chains of poly(HEMA) leads to the carboxylic group formation as shown in Scheme 1. The adjustment of the reaction conditions is of primary importance for the distribution of carboxylic groups on the hydrogel surface and in the bulk. For obtaining the carboxylic groups on the hydrogel surface, it is necessary that hydrolysis rate prevail over the diffusion rate of alkali into the hydrogel.

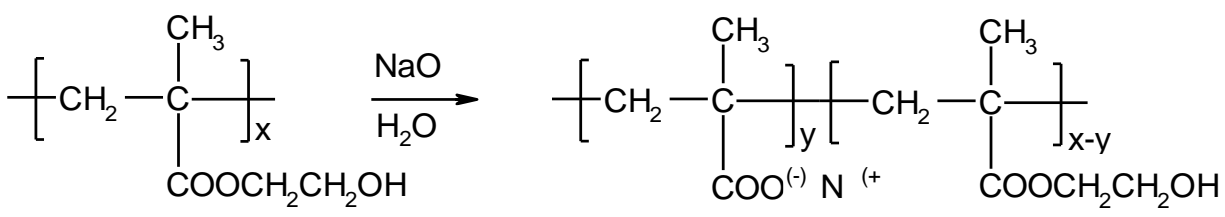

Scheme 1. Hydrolysis of poly(HEMA).

The courses of hydrolysis under different reaction conditions are presented in Fig. 3 as dependences of the total content of carboxylate groups on the reaction time. The temperature effect can be seen on curves $1-3$, the $\mathrm{NaOH}$ concentration effect on curves 2 and 4. An increase in reaction temperature as well as in $\mathrm{NaOH}$ concentration substantially enhances the extent of hydrolysis. 
The dependence of water content in equilibrium-swollen hydrolyzed poly(HEMA) (which has been converted to sodium salt) on the hydrolysis time is shown in Fig. 4. As can be seen from the curves, the water content in hydrogel increases with the reaction time, as well as with $\mathrm{NaOH}$ concentration (curves 2 and 4) and temperature (curves 1 and 2). For the poly(HEMA) hydrolyzed with $27 \mathrm{M} \mathrm{NaOH}$ at $90^{\circ} \mathrm{C}$ for 30 min or with $6 \mathrm{M} \mathrm{NaOH}$ at $90{ }^{\circ} \mathrm{C}$ for $2 \mathrm{~h}$ (curves 2 and 4, Fig. 4), the water content in equilibrium-swollen hydrogel is almost $80 \%$. The values reach those for homogenous copolymers (see "Copolymerization of HEMA and MA") and these hydrogels show also similarly poor mechanical strength. It can be assumed that hydrolysis under these conditions takes place in deep layers.

On the other hand, if the hydrolysis rate is too high (e.g. under high $\mathrm{NaOH}$ concentration or temperature), a high amount of ester surface groups is hydrolyzed in a very short time, which leads to peeling of the modified surface layers due to the swelling pressures exerted by carboxylate ions. This effect was observed in hydrolysis with $6 \mathrm{M} \mathrm{NaOH}$ at $130^{\circ} \mathrm{C}$, when destruction of samples occurred and the swelling degree could not be determined (missing curve 3 in Fig. 4)

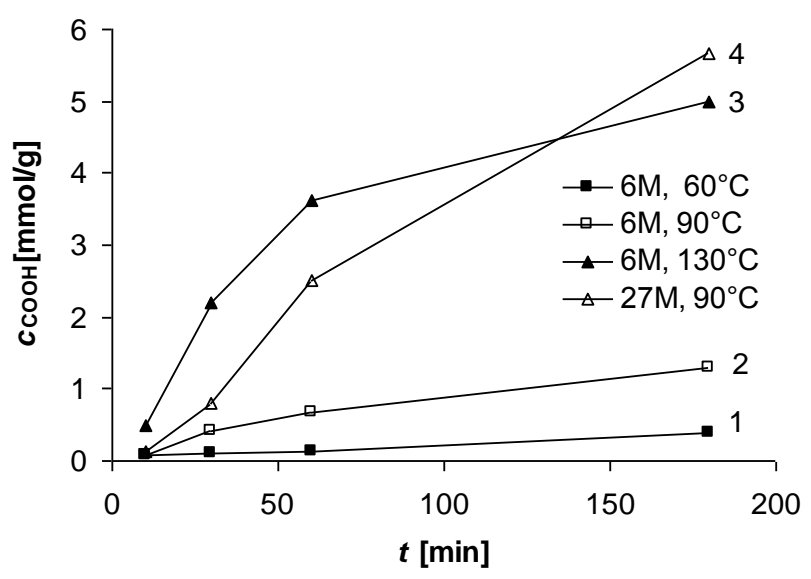

Fig. 3. The dependence of the total carboxylate group content $\left(\mathrm{C}_{\mathrm{COOH}}\right)$ in hydrolyzed poly (HEMA) on the reaction time $(t)$ for different reaction conditions.

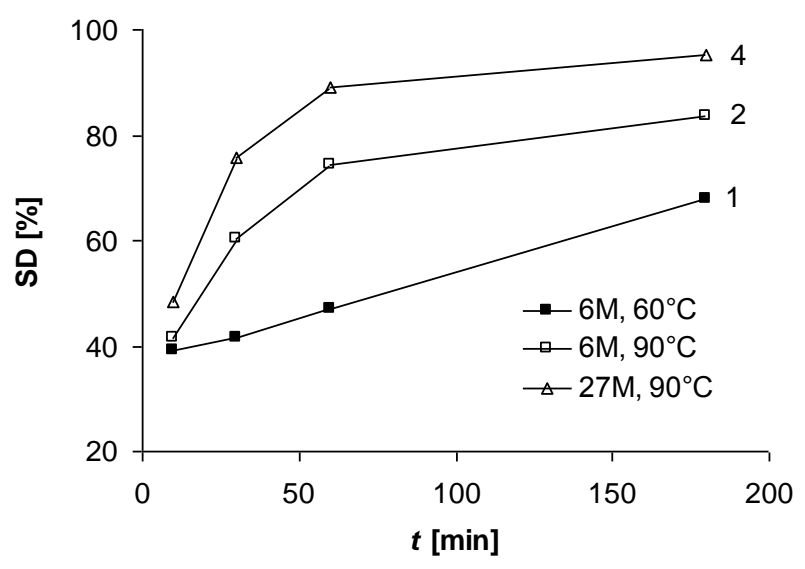

Fig. 4. The dependence of the swelling degree (SD) of hydrolyzed poly(HEMA) in dissociated form on the reaction time $(t)$ for different reaction conditions. 
From the viewpoint of the carboxylic group content and the corresponding mechanical strength dependent on the water content, an acceptable hydrogel arises by hydrolysis with $27 \mathrm{M} \mathrm{NaOH}$ at $90^{\circ} \mathrm{C}$ for $10-30 \mathrm{~min}$, i.e. hydrogel with $\mathrm{COOH}$ content $0.14-0.8 \mathrm{mmol} / \mathrm{g}$ and swelling degree $50-75 \%$.

\section{Oxidation of Poly(HEMA)}

The formation of carboxylic groups on poly(HEMA) modified by oxidation using potassium permanganate proceeds according to Scheme 2.

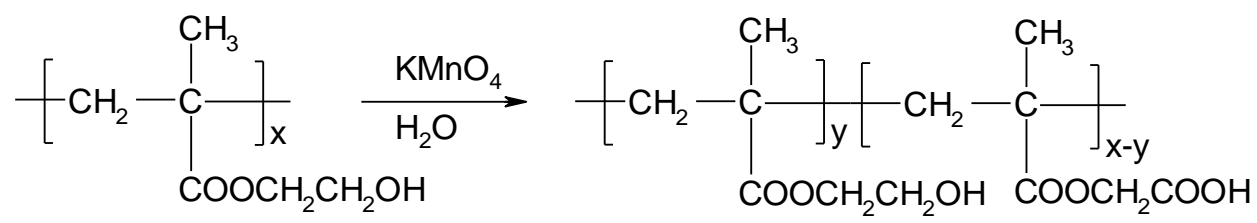

Scheme 2. Oxidation of poly(HEMA) [21].

The course of the $\mathrm{KMnO}_{4}$ oxidation is influenced by $\mathrm{pH}$ of the medium; hence we examined the extent of oxidation reaction under acid or neutral conditions. Besides $\mathrm{pH}$, the ionic strength of $\mathrm{KMnO}_{4}$ solution was controlled by addition of $\mathrm{NaCl}$. Increasing ionic strength of the solution leads to a decrease in the swelling degree of hydrogels: SD of poly(HEMA) hydrogel in water is $39 \%$ whereas in saturated $\mathrm{NaCl}$ solution only $12 \%$. To maintain the lowest swelling degree during the reaction, a solution of $\mathrm{KMnO}_{4}$ in saturated $\mathrm{NaCl}$ solution was used. The results of the oxidation in dependence on the reaction conditions are summarized in Table 1. It can be concluded as following:

(1) The content of carboxylate groups in the hydrogel and its swelling degree are almost independent of the reaction time when an acid solution of permanganate is used (without $\mathrm{NaCl}$ ).

(2) In neutral solution the content of carboxylic groups is insignificantly lower compared with acid solution, but the swelling degree slightly increases. It can be assumed that under these conditions oxidation takes deeper in the hydrogel. From Fig. 2 follows that at the MANa contents in poly(HEMA-co-MANa) copolymers higher than $1 \mathrm{mmol} / \mathrm{g}$, the swelling degree does not significantly change. If approximately the same dependence of the swelling degree on the $\mathrm{COOH}$ content for hydrolyzed poly(HEMA) is taken into account, the increase in the swelling degree is caused by a higher MANa content in the hydrogel bulk. It is particularly evident for the reaction time $20 \mathrm{~h}$, when the MANa content increased only slightly, but the swelling degree increased significantly.

(3) Increasing the $\mathrm{KMnO}_{4}$ concentration three times has no significant influence on the carboxylate content or the swelling degree when compared to item 1 in Table 1.

(4) Addition of $\mathrm{NaCl}$ to acid $\mathrm{KMnO}_{4}$ solution leads to a lower extent of hydrogel oxidation but its swelling degree increases only slightly compared with neat poly(HEMA) hydrogel. It follows that the oxidation takes place predominantly on the surface.

(5) Under the given conditions (item 5, Table 1), i.e. without addition of acid, the carboxylate content substantially increased. At the same time, the swelling degree also increased, though not so much as for a homogenous copolymer. This suggests 
that the oxidation under these conditions is most effective, but takes places in the hydrogel bulk.

From the viewpoint of the $\mathrm{COOH}$ and water content and the corresponding mechanical behaviour, an acceptable hydrogel arises under the conditions marked by "*” in Table 1.

Tab. 1. The carboxylate (COONa) and water contents in equilibrium-swollen oxidized poly(HEMA) hydrogels in dependence on the reaction conditions.

\begin{tabular}{|c|c|c|c|c|}
\hline \multicolumn{2}{|c|}{ Oxidation } & $\begin{array}{l}\text { Time } \\
\text { (h) }\end{array}$ & $\begin{array}{l}\text { COONa content } \\
(\mathrm{mmol} / \mathrm{g})\end{array}$ & $\begin{array}{c}\text { Swelling degree } \\
(\%)\end{array}$ \\
\hline \multirow[t]{3}{*}{1} & $2 \% \mathrm{KMnO}_{4}$ & 1 & 0.74 & $69.8^{*}$ \\
\hline & $\mathrm{H}_{2} \mathrm{O}$ solution & 3 & 0.91 & $70.1^{*}$ \\
\hline & acid & 6 & 0.90 & 73.9 \\
\hline \multirow[t]{3}{*}{2} & $2 \% \mathrm{KMnO}_{4}$ & 3 & 0.58 & $72.1^{*}$ \\
\hline & $\mathrm{H}_{2} \mathrm{O}$ solution & 6 & 0.68 & 74.6 * \\
\hline & neutral & 20 & 0.74 & 87.3 \\
\hline \multirow[t]{3}{*}{3} & $6 \% \mathrm{KMnO}_{4}$ & 1 & 0.79 & 77.4 \\
\hline & $\mathrm{H}_{2} \mathrm{O}$ solution & 3 & 0.77 & 77.4 \\
\hline & acid & 6 & 0.90 & 73.3 \\
\hline \multirow[t]{4}{*}{4} & $2 \% \mathrm{KMnO}_{4}$ & 1 & 0.10 & 40.5 \\
\hline & $\mathrm{NaCl}$ solution & 3 & 0.19 & $42.3^{*}$ \\
\hline & acid & 6 & 0.24 & 42.4 * \\
\hline & & 20 & 0.41 & $45.1^{*}$ \\
\hline \multirow[t]{4}{*}{5} & $2 \% \mathrm{KMnO}_{4}$ & 1 & 0.50 & $46.8^{*}$ \\
\hline & $\mathrm{NaCl}$ solution & 3 & 0.96 & 63.8 * \\
\hline & neutral & 6 & 1.40 & 81.2 \\
\hline & & 20 & 3.41 & 84.2 \\
\hline
\end{tabular}

${ }^{a}$ water content of oxidized poly(HEMA) converted to sodium salt

\section{Characterization of Modified Poly(HEMA)}

\section{-ATR-FTIR Spectroscopy}

The changes in chemical structure of the surface layers in modified poly(HEMA) were monitored by ATR FT-IR spectroscopy. Figure 5 shows the spectra of oxidized poly(HEMA) under different reaction conditions. In all spectra the characteristic $\mathrm{OH}$ stretch as a broad peak at $3300 \mathrm{~cm}^{-1}$ was detected, which indicates the presence of some unmodified HEMA units. In the region between 1550 and $1730 \mathrm{~cm}^{-1}$ are evident two signals characterizing stretching vibration of carbonyl groups, while the peak at $1720 \mathrm{~cm}^{-1}$ corresponds to ester group and the peak at $1595 \mathrm{~cm}^{-1}$ to carboxylate group, respectively. The appearance of carboxylate groups in all the spectra demonstrates that the partial oxidation of 2-hydroxyethyl ester groups was successful. A comparison of the intensity of ester and carboxylate groups shows that the oxidation of the surface is more effective using an aqueous $\mathrm{KMnO}_{4}$ solution than in the case of the solution containing $\mathrm{NaCl}$. 


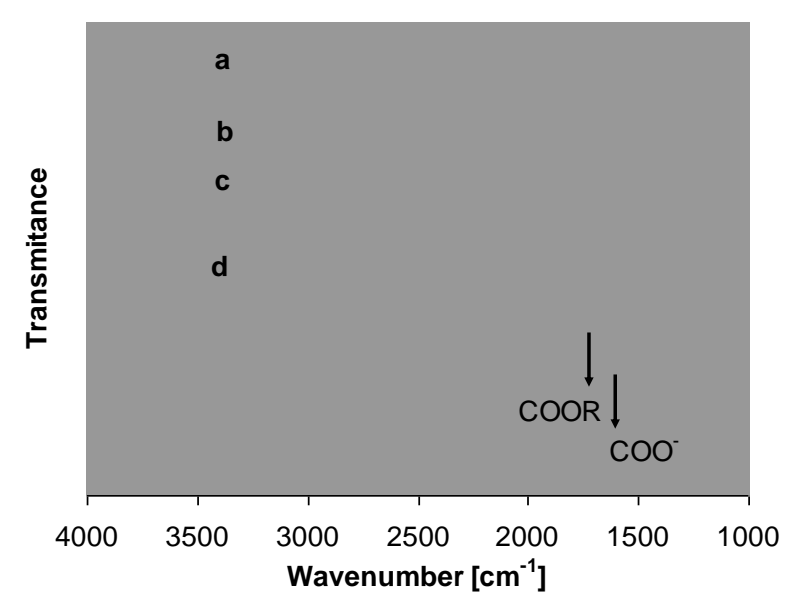

Fig. 5.ATR-FTIR spectra of oxidized poly(HEMA) under different reaction conditions: a) pure poly(HEMA), b) $\mathrm{NaCl}$, acid, $3 \mathrm{~h}, \mathrm{c}) \mathrm{NaCl}$, neutral, $3 \mathrm{~h}$, d) $\mathrm{H}_{2} \mathrm{O}$, acid, $3 \mathrm{~h}$.

\section{-Refractive Index Measurements}

The refractive index of equilibrium-swollen hydrogels is closely related to the equilibrium content of water in the gel.

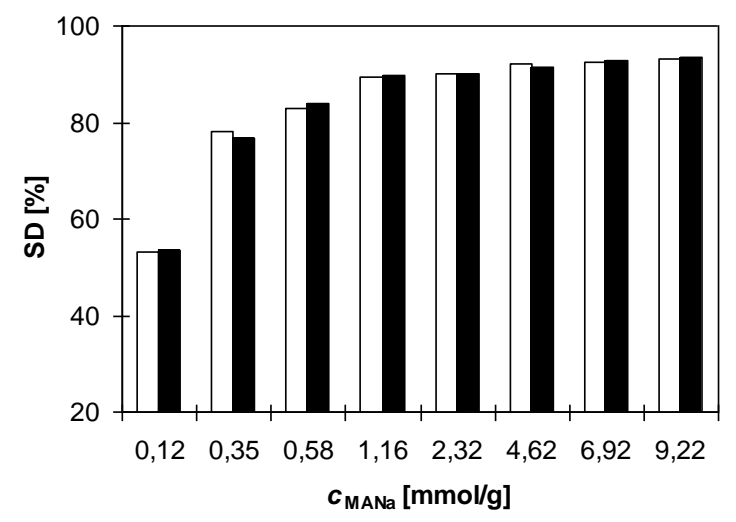

Fig. 6. Swelling degrees (SD) of poly(HEMA-co-MANa) copolymers obtained by weighing $(\square)$ and refractive index measurements $(\mathbf{})$.

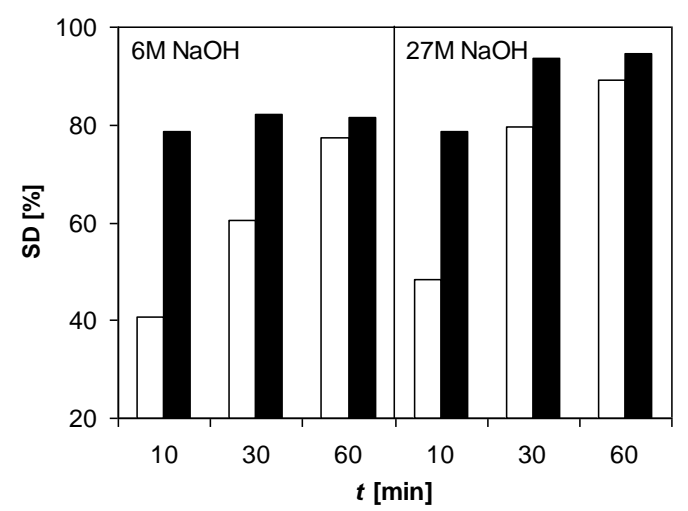

Fig. 7.Swelling degrees (SD) of hydrolyzed poly(HEMA) (with $6 \mathrm{M}$ or $27 \mathrm{M} \mathrm{NaOH}$ at $90^{\circ} \mathrm{C}$ ) obtained by weighing $(\square)$ and refractive index measurements $(\mathbf{\square})$. 
At the same time, the knowledge of the density and refractive index of a xerogel makes it possible to determine the swelling degree of hydrogels and confirm this important characteristic by independent measurements. Moreover, refractive index is an important parameter for potential optical applications of the hydrogels as polymer supports for cultivation of limbal cells in the preparation of artificial cornea. A comparison of the swelling degrees (SD) derived from the measured refractive indexes and those calculated after weighing swollen and dry hydrogels are shown in Fig. 6-8. In the case of poly(HEMA-Co-MANa) copolymers (Fig. 6) the values of SD are almost identical in the whole concentration range, while the values of SD for hydrolyzed (Fig. 7) and oxidized poly(HEMA) (Fig. 8) are considerably different. This indicates that the modified hydrogels are not homogenous and that the modification reaction does not proceed in the bulk of the hydrogel. It follows from Fig. 7 that the difference between SD determined by weighing and refractive index measurements decreases with increasing hydrolysis time. With extended reaction time, hydrogels swells more and, therefore, hydrolysis takes place more in the bulk.

A different situation is observed for oxidized poly(HEMA) (Fig. 8). In the case of acid aqueous $\mathrm{KMnO}_{4}$ solution, the $\mathrm{SD}$ determined by weighing is only slightly lower than the SD obtained from refractive index measurements regardless of the reaction time. In contrast, the presence of $\mathrm{NaCl}$ in solution, which guarantees a low $\mathrm{SD}$ during the reaction, allows oxidation to exclusively proceed on the surface. This is demonstrated by the substantially different values of SD determined by weighing and refractive index measurements, suggesting the formation of significantly non-homogeneous hydrogels by oxidation under these conditions.

Qualitative observation of the modification reaction on the hydrogel surface by refractive index measurements well corresponds with the results discussed above concerning the relationships of the $\mathrm{COOH}$ content and the water content.

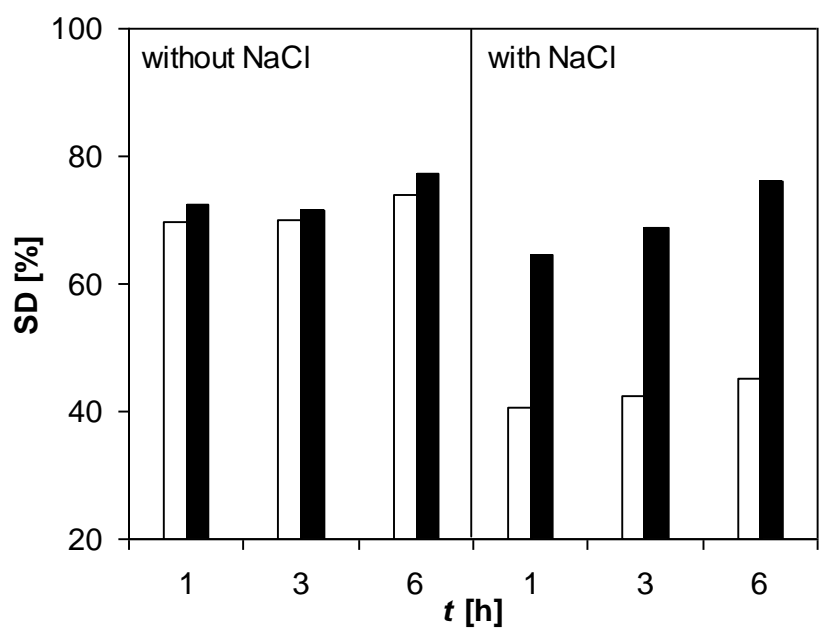

Fig. 8.Swelling degrees of oxidized poly(HEMA) (with $2 \%$ acid $\mathrm{KMnO}_{4}$ solution without or with addition of $\mathrm{NaCl}$ ) obtained by weighing ( $\square$ ) and refractive index measurements ( $\mathbf{\square})$.

\section{Immobilization of Avidin on the Hydrogel Surface}

Avidin has been immobilized on the hydrogel surface through electrostatic interactions or through covalent bonds. To realize electrostatic interactions, 
carboxylic groups of hydrogels were converted to carboxylates by neutralization with $\mathrm{NaHCO}_{3}$. For the covalent attachment of avidin to the hydrogel surface, carboxylic groups must be activated. In the present work, the reaction with NHS in the presence of a water-soluble carbodiimide (EDC) was used (Scheme 3).

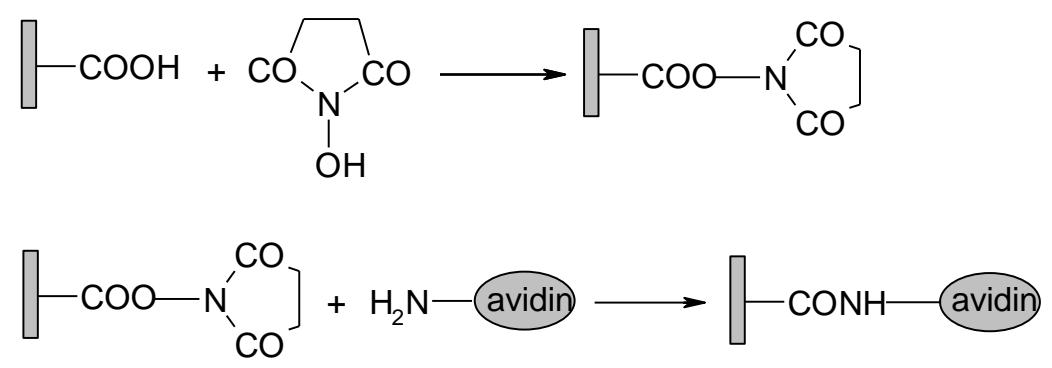

Scheme 3. Activation of carboxylic groups by $\mathrm{N}$-hydroxysuccinimide for covalent attachment of avidin.

The capacity of selected hydrogels for electrostatically and covalently immobilized avidin was calculated using Equation 3 and summarized in Table 2. In the case of poly(HEMA-co-MANa) copolymers, the amount of electrostatically immobilized avidin grows with the growing MANa content, with a significant increase (by two orders) in the range $0.58-1.16 \mathrm{mmol} / \mathrm{g}$ MANa. This suggests that for the MANa content ca $1 \mathrm{mmol} / \mathrm{g}$, the amount of the surface charge is sufficient for the accomplishment of electrostatic sorption. The capacity values of the order of tenths milligrams are comparable with those obtained for neat poly(HEMA), where the immobilization of avidin proceeds through non-specific interactions.

In contrast, the capacity values for covalently bound avidin are almost independent of the $\mathrm{COOH}$ content and are significantly lower than those for electrostatic sorption. This difference can be explained by steric hindrance to the formation of covalent links between the hydrogel surface and bulky molecules of avidin. To a certain extent, the distribution of carboxylic groups on the surface may also play an important role. All these factors have an influence on the reaction of a limited number of carboxylic groups regardless of their initial number, and thus the amount of covalently bound avidin does not change with the $\mathrm{COOH}$ content. Another explanation of the significant differences in the capacity values depending on the way of avidin immobilization is that in electrostatic sorption the charge transfer within the molecule of avidin may occur, and thus multilayer coatings are formed.

In hydrolyzed poly(HEMA), the amount of electrostatically immobilized avidin is almost constant, regardless of the reaction time. This confirms the results discussed above that hydrolysis of the surface 2-hydroxyethyl ester groups proceeds very fast (in minutes). Hence, the COONa content does not change after some time and with increasing time the reaction takes place only in the bulk of the hydrogel. In oxidized poly(HEMA), the amount of electrostatically immobilized avidin slightly increases with increasing reaction time. Significantly higher values of the avidin capacity have been achieved for hydrogels oxidized with acid aqueous $\mathrm{KMnO}_{4}$ solution without $\mathrm{NaCl}$ than in the presence of $\mathrm{NaCl}$. This corresponds with the COONa content obtained by oxidation under the reaction conditions in Table 1. The hydrogels obtained by oxidation in the absence of $\mathrm{NaCl}$ show about five times higher $\mathrm{COONa}$ contents than those oxidized in the presence of $\mathrm{NaCl}$. However, the capacities are about thirty times higher, which demonstrates the multiple-layer sorption of avidin. 
For the surface-modified hydrogels, the amount of electrostatically immobilized avidin was in the range $10-20 \mathrm{mg} / \mathrm{g}$ at lower total COONa contents (see Fig. 3 and Table 1) than for poly(HEMA-co-MANa) copolymers. This fact confirms the achievement of increased carboxylic group content on the surface rather than in the bulk of the hydrogel. An interesting finding is that the values of the capacity for covalently bonded avidin are 3-4 times higher for surface-modified hydrogels than for the copolymers. This suggests that the distribution of the carboxylic groups in these hydrogels is more favourable for the formation of covalent linkages.

In addition, it should be mentioned that reversible desorption of avidin, regardless of the method of immobilization, does not proceed. After immobilization, hydrogels were put into fresh saline and the concentration of avidin in the solution was measured after 24,48 , and $72 \mathrm{~h}$. No protein could be detected in the solution.

Tab. 2. The capacity of the hydrogel surfaces for avidin immobilization.

\begin{tabular}{lcc}
\hline Hydrogel & $\begin{array}{c}\text { Capacity } \\
(\mathrm{mg} / \mathrm{g})\end{array}$ & $\begin{array}{c}\text { Capacity } \\
(\mathrm{mg} / \mathrm{g})\end{array}$ \\
\hline Poly(HEMA-MA) & & \\
(MA content, mmol/g) & & \\
\hline 0,35 & 0.21 & 0.12 \\
0,58 & 0.57 & 0.15 \\
1,16 & 14.24 & 0.09 \\
4,63 & 34.80 & 0.12 \\
\hline
\end{tabular}

Hydrolyzed poly(HEMA)

$\left(27 \mathrm{M} \mathrm{NaOH}, 90^{\circ} \mathrm{C}\right)$

\begin{tabular}{lll}
$10 \mathrm{~min}$ & 11.90 & 0.39 \\
$30 \mathrm{~min}$ & 13.00 & 0.39 \\
$60 \mathrm{~min}$ & 12.70 & 0.36 \\
\hline
\end{tabular}

Oxidized poly(HEMA)

$\left(2 \% \mathrm{KMnO}_{4}, \mathrm{H}_{2} \mathrm{O}\right.$, acid $)$

\begin{tabular}{ll}
\hline $1 \mathrm{~h}$ & 18.70 \\
$3 \mathrm{~h}$ & 21.20 \\
\hline
\end{tabular}

\begin{tabular}{lll}
$\left(2 \% \mathrm{KMnO}_{4}, \mathrm{NaCl}\right.$, acid $)$ & & \\
\hline $1 \mathrm{~h}$ & 0.47 & 0.27 \\
$3 \mathrm{~h}$ & 0.95 & 0.34 \\
\hline
\end{tabular}

a electrostatically bonded avidin

${ }^{\mathrm{b}}$ covalently bonded avidin

As described above, hydrogels with immobilized avidin were obtained, and the avidin content significantly differs depending on the way of immobilization. It appeared, that through electrostatic sorption it is possible to immobilize a higher amount of avidin, but due to possible local changes in $\mathrm{pH}$ during the cell culture process, the partial desorption may occur. Capacity of hydrogels for avidin immobilization via covalent bonds is lower, but some advantages of this method consist in stability of covalent bonds forming between avidin and hydrogel surface. 
Detailed study on the influence of the amount and the way of avidin immobilization will be the subject of the further work. However, the preliminary biological tests using some selected hydrogels were evaluated. The cultivation process of human keratinocytes without feeder cells has been studied in series of hydrogel + keratinocytes and hydrogel + avidin + keratinocytes. On the Fig. 9 are shown the results of keratinocytes cultivation after 7 days on the hydrogel supports oxidized using acid $\mathrm{KMnO}_{4}$ solution in the presence of $\mathrm{NaCl}$ for $3 \mathrm{~h}$. The surface of pure oxidized poly(HEMA) was colonized by a very low number and poorly spread keratinocytes (Fig. 9A). In the case of hydrogel surface modified by electrostatically bound avidin, the improvement in adhesion and proliferation of cells was achieved (Fig. 9B). These initial results of biological tests showed that the introduction of protein to the hydrogel surface has a positive effect on the cell response.

Avidin-modified hydrogels offer the possibility of incorporation of various bioactive motifs through the reaction of their biotinylated forms forming the complex avidinbiotin. Selecting an appropriate motif, the supports for cultivation of targeted type of cells can be prepared, e.g. glycoligand containing mannose is the desirable motif for the cultivation of human keratinocytes [20].

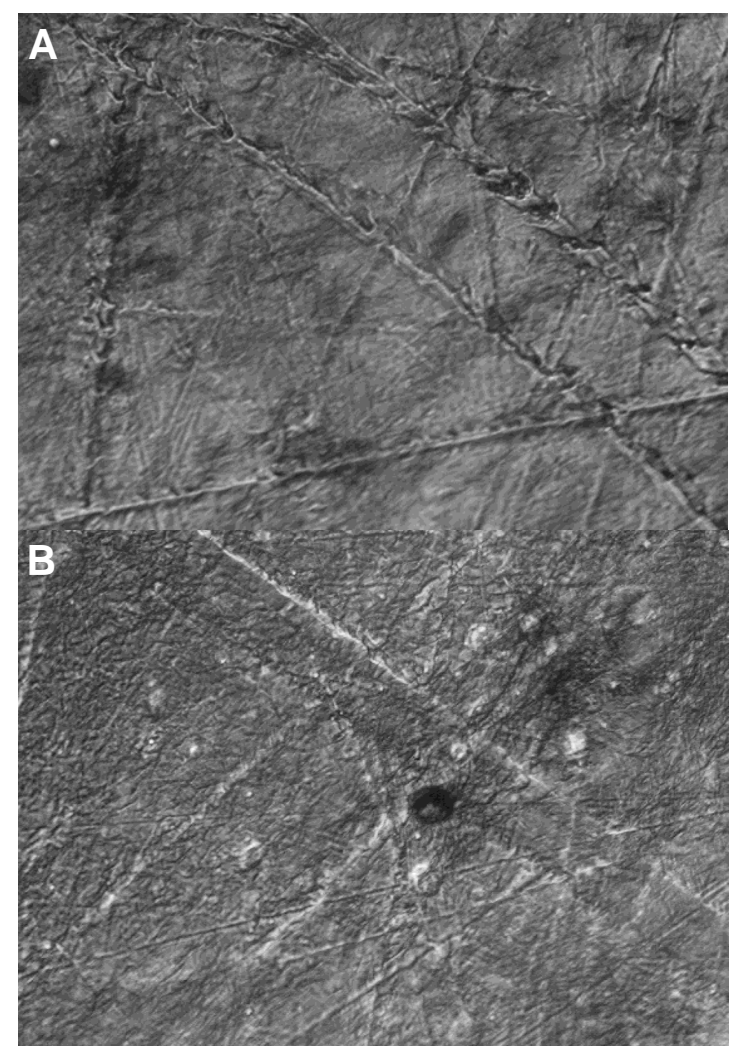

Fig. 9. Optical microscope images of human keratinocytes cultivation after 7 days seeding on the surfaces of oxidized poly(HEMA) (acid $\mathrm{KMnO}_{4}$ solution in the presence of $\mathrm{NaCl}$ for $3 \mathrm{~h}$ ). A - pure oxidized poly(HEMA) surface, B - oxidized poly(HEMA) surface modified by electrostatically bound avidin.

\section{Conclusions}

In this work, three methods for preparation $\mathrm{COOH}$-containing hydrogels were used: copolymerization of HEMA and MA, hydrolysis of poly(HEMA) and oxidation of poly(HEMA). For determination of the total carboxylic group content, a suitable 
method was potentiometric titration. The presence of $\mathrm{COOH}$ groups on the hydrogel surface was confirmed by ATR FT-IR spectroscopy showing absorption of $1595 \mathrm{~cm}^{-1}$ corresponding to carboxylate groups.

Examination of the relation between the $\mathrm{COOH}$ content in hydrogels and its swelling degree suggests that the adjustment of the reaction conditions is of primary importance for defining final surface, and for material properties, in particular mechanical strength. Hydrogels obtained by hydrolysis with high concentrated $\mathrm{NaOH}$ solution $(27 \mathrm{M})$ at elevated temperatures $\left(90^{\circ} \mathrm{C}\right)$ for short reaction times $(10-30 \mathrm{~min})$ or by oxidation with acid $\mathrm{KMnO}_{4}$ solution in the presence or absence of $\mathrm{NaCl}$ were found with regard to $\mathrm{COOH}$ and water content as the most suitable for subsequent use.

To surface-modified hydrogels, avidin was successfully immobilized via electrostatic sorption or covalent bonding. Preliminary biological tests showed that the presence of avidin bound to the hydrogel surface improves the adhesion and proliferation of keratinocytes cultured without feeder cells. With the possibility of incorporation of bioactive motifs specific for a particular type of cells to the surface through complex avidin-biotin, hydrogels with immobilized avidin suggests to be suitable candidates for using as a universal cultivation supports.

\section{Experimental part}

\section{Chemicals}

Methacrylic acid (MA) (Fluka) was distilled before use. 2-Hydroxyethyl methacrylate (HEMA) (99\%, Roehm GmbH), ethylene dimethacrylate (EDMA), benzoin ethyl ether (BEE; UV initiator), 1-[3-(dimethylamino)propyl]-3-ethyl-carbodiimide hydrochloride (EDC), N-hydroxysuccinimide (NHS), avidin (all Fluka), and Coomassie Brilliant Blue $\mathrm{G}$ (CBB) (Aldrich) were used without purification.

\section{Hydrogel Preparation}

Hydrogels were prepared by crosslinking radical polymerization of HEMA and MA monomers (total $10 \mathrm{~g})$, with EDMA $(0.05 \mathrm{~g})$ with BEE $(0.05 \mathrm{~g})$ after bubbling with nitrogen $(5 \mathrm{~min})$ in the mould formed by a polypropylene plate, silicone-rubber distance frame $(0.5 \mathrm{~mm}$ thick, $5 \mathrm{~cm} \times 5 \mathrm{~cm})$ and glass plate. The polymerization mixture was illuminated with UV lamp ReptiGlo 8.0 (60 W) (Hagen, Czech Republic) for $20 \mathrm{~min}$ at room temperature. After polymerization, hydrogels were washed with water for 5 days to remove soluble substances.

The water content in equilibrium-swollen hydrogel, swelling degree (SD), was calculated as

$\mathrm{SD}=\left(m_{\mathrm{s}}-m_{\mathrm{d}}\right) / m_{\mathrm{s}} \times 100[\%]$

where $m_{\mathrm{s}}$ and $m_{\mathrm{d}}$ are the weights of swollen and dry hydrogel, respectively.

\section{Surface Modification of Poly(HEMA) Hydrogels}

\section{-Hydrolysis}

The hydrolysis of ester groups of poly(HEMA) was performed by using aqueous $\mathrm{NaOH}\left(6\right.$ and $27 \mathrm{M}$ ). The reaction was carried out at 60,90 and $130^{\circ} \mathrm{C}$ for $10,30,60$ and 180 min under stirring. The hydrolysis was stopped by immersing the hydrogels 
into $1 \mathrm{M} \mathrm{HCl}$. They were then washed with water (3x, 2 days), dried under reduced pressure and weighed. The hydrolysis has given copolymers of HEMA and MA (poly(HEMA-co-MA)). The carboxylic group content $\left(\mathrm{C}_{\mathrm{COOH}}\right)(\mathrm{mmol}$ per $\mathrm{g}$ of dry hydrogel) was calculated as

$c_{\mathrm{COOH}}=\left(W_{0}-W_{1}\right) /\left(44.05 \times W_{1}\right) \times 1000 \quad[\mathrm{mmol} / \mathrm{g}]$

where $W_{0}$ and $W_{1}$ are the weights of the original poly(HEMA) and resulting poly(HEMA-co-MA), respectively, and 44.05 is the difference between the molecular weight of HEMA and MA monomeric unit.

\section{-Oxidation}

Hydroxy groups of poly(HEMA) were oxidized with potassium permanganate to yield carboxylic groups as described earlier [21, 22]. The oxidation was performed using $2 \%$ solution of $\mathrm{KMnO}_{4}$ in aqueous or $\mathrm{NaCl}$-saturated solution with or without addition of sulfuric acid at room temperature. The reaction time was $1-20 \mathrm{~h}$. The excess of permanganate was removed with three portions of $10 \mathrm{wt} \%$ oxalic acid and the hydrogels were then washed with water (3x, 2 days).

\section{Activation of Carboxylic Groups}

Carboxylic groups on the hydrogel surface were activated by the reaction with NHS in the presence of water-soluble carbodiimide EDC by immersing the hydrogel into aqueous $0.1 \mathrm{M} \mathrm{NHS}$ with an equimolar amount of EDC and $40 \mathrm{~h}$ shaking at room temperature.

\section{Characterization of Modified Hydrogels}

Chemical composition of the prepared hydrogels was determined by $\mathrm{CHN}$ elemental analysis (Perkin-Elmer CHN 2400). The $\mathrm{Na}^{+}$-ion content was determined by AAS on a Perkin-Elmer 3110. The changes in chemical structure of the hydrogel surface layer were examined by ATR FT-IR on a spectrometer Perkin-Elmer paragon 1000PC equipped with ATR adapter. The refractive indexes of equilibrium-swollen hydrogels were measured with an Abbe refractometer at $20^{\circ} \mathrm{C}$.

\section{Determination of the Carboxylic Group Content}

The extent of modifying reactions was determined by potentiometric titration. The $\mathrm{COOH}$ groups of modified poly(HEMA) were allowed to react with aqueous solution of sodium hydrogencarbonate. Afterwards, the concentration of $\mathrm{NaHCO}_{3}$ was determined by titration with $0.1 \mathrm{M} \mathrm{HCl}$. The $\mathrm{COOH}$ content was calculated from the $\mathrm{NaHCO}_{3}$ concentration difference before and after immersion of the hydrogels.

\section{Immobilization of Avidin}

Equilibrium-swollen hydrogels were put into a saline of avidin and maintained there for $15 \mathrm{~h}$. The concentration of avidin in the solution $(c)$ was determined by the Bradford spectrophotometric method [23] using a Helios Beta spectrometer (Thermo Spectronic, UK). Cuvettes with a solution of avidin and dye CBB were heated at $100{ }^{\circ} \mathrm{C}$ for $20 \mathrm{~min}$ and, after cooling to room temperature, the absorption at $595 \mathrm{~nm}$ was measured [24].

The capacity of hydrogel support for avidin immobilization $(S)$ was calculated as 
$S=\left(V_{0} c_{0}-V_{0} c\right) / m_{d} \times 1000 \quad[\mathrm{mg} / \mathrm{g}]$

where $c_{0}=0.5 \mathrm{mg} / \mathrm{ml}, V_{0}(\mathrm{ml})$ is the volume of avidin solution and $m_{\mathrm{d}}(\mathrm{g})$ is the weight of dry hydrogel.

\section{Cell Culture Assay}

Keratinocytes were isolated from residual human skin obtained with informed consent of donors from the Department of Aesthetic Surgery, Charles University, $3^{\text {rd }}$ Faculty of Medicine, Prague. Using trypsinization the epidermis and dermis were separated and from the dermis hair follicle keratinocytes were prepared and maintained as reported previously [25]. Hair follicle keratinocytes, the $3^{\text {rd }}$ subculture, were used in the experiments. The testing was performed with polymer discs $(13 \mathrm{~mm}$ in diameter) prepared from modified poly(HEMA) without or with avidin bound to the surface in series hydrogel + cells, hydrogel + avidin + cells. The hydrogel discs were placed to 24-well culture plates (Nucleon, Nunc, Denmark) and soaked in PBS (phosphate buffered saline, Biochrome, Berlin, Germany) for 1 day. Keratinocytes were seeded in the density 40000 cells $/ \mathrm{cm}^{2}$ cultured without feeder cells in DMEM/F12 (3:1) medium (Dulbecco's Modified Eagle's Medium/Ham's Nutrient Medium, Biochrome, Berlin, Germany) supplemented with $10 \%$ fetal bovine serum (Biochrome, Berlin, Germany) and special additives [26] and cultured at $37^{\circ} \mathrm{C}$ and $5 \% \mathrm{CO}_{2}$ for 7 days. Culture medium was changed every two days. The extent of cell proliferation was analysed using inverse optical microscope IX 71 with computer assisted camera DP 50 (Olympus, Prague, Czech Republic).

\section{Acknowledgements}

This work was supported by the Academy of Sciences of the Czech Republic (project 1QS400500558). The authors thank B. Dvořánková, Ph.D. for implementing the pilot biological experiments.

\section{References}

[1] Goddard, J. M.; Hotchkiss, J. H. Prog. Polym. Sci. 2007, 32, 698.

[2] Ma, Z.; Mao, Z.; Gao, C. Colloids Surf. B-Biointerfaces 2007, 60. 137.

[3] Vasita, R.; Shanmugan, K.; Katti, D. S. Curr. Top. Med. Chem. 2008, 8, 341.

[4] Baroli, B. J. Pharm. Sci. 2007, 96, 2197.

[5] Nicodemus, G. D.; Bryant, S. J. Tissue Eng. Part B: Rev. 2008, 14, 149.

[6] Wilchek, M.; Bayer, E. A. Introduction to Avidin-Biotin Technology, in: Wilchek, M.; Bayer, E. A.; Methods in Enzymology, Academic Press Inc., San Diengo, 1990, pp. 5-13.

[7] Tsai, W. B.; Wang, M. C. Macromol. Biosci. 2005, 5, 214.

[8] Tsai, W. B.; Wang, P. Y.; Chang, Y; Wang, M. C. Biotechnol. Bioeng. 2007, 98, 498.

[9] Kojima, N.; Matsuo, T.; Sakai, Y. Biomaterials 2006, 27, 4904.

[10] Anamelechi, C. C.; Truskey, G. A.; Reichert, W. M. Biomaterials 2005, 26, 6887.

[11] Vermette, P.; Gengenbach, T.; Divisekere, U.; Kambouris, P. A.; Griesser, H. J.; Meagher, L. J. Colloid Interface Sci. 2003, 259, 13.

[12] Misawa, N.; Yamamura, S.; Yong-Hoon, K.; Tero, R.; Nonogaki, Y.; Urisu, T. Chem. Phys. Lett. 2006, 419, 86.

[13] Klouda, L.; Mikos, A. G. Eur. J. Pharm. Biopharm. 2008, 68, 34. 
[14] Schmidt, J. J.; Rowley, J.; Hyun, J. K. J. Biomed. Mat. Res. - Part A 2008, 87, 113.

[15] Sun, Y.; Maughan, J.; Haigh, R.; Hopkins, S. A.; Wyman, P.; Johnson, C.; Fullwood, N. J.; Ebdon, J.; MacNeil, S.; Rimmer, S. Macromol. Symp. 2007, 256, 137.

[16] Montheard, J. P.; Chatzopoulos, M.; Chappard, D. J. Macromol. Sci-Rev. Macromol. Chem. Phys. 1992, C32, 1.

[17] Khutoryanskaya, O. V.; Mayeva, Z. A.; Mun, G. A.; Khutoryanskiy, V. V. Biomacromolecules 2008, 9, 3353.

[18] Mabilleau, G.; Stancu, I. C.; Honore, T.; Legeay, G.; Cincu, C.; Basle, M. F.; Chappard, D. J. Biomed. Mater. Res., Part A 2006, 77, 35.

[19] Michálek, J.; Přádný, M.; Artyukhov, A.; Šlouf, M.; Smetana K. Jr.; J. Mater. Sci. Mater. Med. 2005, 16, 783.

[20] Labský, J.; Dvořánková, B.; Smetana K. Jr.; Holíková, Z.; Brož, L.; Gabius, H. J. Biomaterials 2003, 24, 863.

[21] Mikeš, O.; Štrop, P.; Smrž, M.; Čoupek, J. J. Chromatogr. 1980, 1962, 159.

[22] Horák, D.; Rittich, B.; Španová, A.; Beneš, M. Polymer 2005, 46, 1245.

[23] Bradford, M. M. Anal. Biochem. 1976, 72, 248.

[24] Sharma, H. K.; Tihon, C. Anal. Biochem. 1988, 170, 135.

[25] Purkrábková, T.; Smetana K. Jr.; Dvořánková, B.; Holíková, Z.; Böck, C.; Lensch, M.; André, S.; Pytlík, R.; Liu, F. T.; Klíma, J.; Smetana, K.; Motlík, J.; Gabius, H. J. Biol. Cell 2003, 95, 535.

[26] Matoušková, E.; Veselý, P.; Königová, R. Folia Biol. (Prague) 1989, 35, 267. 